pteruges, and a Macroglossus, also a species of Scotophilus, probably $S$. nigrogriseus, Gould.

The fishes were not numerous, but some interesting species were obtained, respecting which the Hon. Wm. Macleay read some remarks which will be published in due time.

The insects, about fifty species, will also we hope be taken up by Mr. Macleay. Among the spiders are some very interesting forms, apparently quite new.

The collection of birds numbers about 350 specimens, the mammals about 120 . Spirit specimens about 100 .

We believe a large portion of this fine collection has been secured by the curator, Mr. E. P. Ramsay, F.L.S., for the Australian Museum.

\section{THE SORTING DEMON OF MAXWELL ${ }^{1}$}

THE word "demon," which originally in Greek meant 1 a supernatural being, has never been properly used to signify a real or ideal personification of malignity.

Clerk Maxwell's "demon" is a creature of imagination having certain perfectly well-defined powers of action, purely mechanical in their character, invented to help us to understand the "Dissipation of Energy" in nature.

$\mathrm{He}$ is a being with no preternatural qualities, and differs from real living animals only in extreme smallness and agility. He can at pleasure stop, or strike, or push, or pull any single atom of matter, and so moderate its natural course of motion. Endowed ideally with arms and hands and fingers - two hands and ten fingers suffice -he can do as much for atoms as a pianoforte player can do for the keys of the piano-just a little more, he can push or pull each atom in any direction.

He cannot create or annul energy; but just as a living animal does, he can store up limited quantities of energy, and reproduce them at will. By operating selectively on individual atoms he can reverse the natural dissipation of energy, can cause one-half of a closed jar of air or of a bar of iron to become glowingly hot and the other icecold ; can direct the energy of the moving molecules of a basin of water to throw the water up to a height and leave it there proportionately cooled $\left(\mathrm{I}^{\circ} \mathrm{Fahr}\right.$. for 772 feet of ascent); can "sort": the molecules in a solution of salt or in a mixture of two gases, so as to reverse the natural process of diffusion, and produce concentration of the solution in one portion of the water, leaving pure water in the remainder of the space occupied; or, in the other case, separate the gases into different parts of the containing vessel.

"Dissipation of energy" follows in nature from the fortuitous concourse of atoms. The lost motivity is essentially not restorable otherwise than by an agency dealing with individual atoms; and the mode of dealing with the atoms to restore motivity is essentially a process of assortment, sending this way all of one kind or class, that way all of another kind or class.

The classification, according to which the ideal demon is to sort them, may be according to the essential character of the atom; for instance, all atoms of hydrogen to be let go to the left, or stopped from crossing to the right, across an ideal boundary; or it may be according to the velocity each atom chances to have when it approaches the boundary : if greater than a certain stated amount, it is to go to the right; if less, to the left. This latter rule of assortment, carried into execution by the demon, disequalises temperature, and undoes the natural diffusion of heat; the former undoes the natural diffusion of matter.

By a combination of the two processes, the demon can decompose water or carbonic acid, first raising a portion of the compound to dissociational temperature (that is, temperature so high that collisions shatter the compound

- Abstract of Lecture at the Royal Institution, Friday, February 28, 1879 , by Six William Thomson, LL.D., F.R.S. molecules to atoms), and then sending the oxygen atoms this way, and the hydrogen or carbon atoms that way; or he may effect decomposition against chemical affinity otherwise, thus : Let him take in a small store of energy by resisting the mutual approach of two compound molecules, letting them press, as it were, on his two hands, and store up energy as in a bent spring; then let him apply the two hands between the oxygen and the double hydrogen constituents of a compound molecule of vapour of water, and tear them asunder. He may repeat this process until a considerable proportion of the whole number of compound molecules in a given quantity of vapour of water, given in a fixed closed vessel, are separated into oxygen and hydrogen at the expense of energy taken from translational motions. The motivity (or energy for motive power) in the explosive mixture of oxygen and hydrogen of the one case, and the separated mutual combustibles, carbon and oxygen, of the other case, thus obtained, is a transformation of the energy found in the substance in the form of kinetic energy of the thermal motions of the compound molecules. Essentially different is the decomposition of carbonic acid and water in the natural growth of plants, the resulting motivity of which is taken from the undulations of light or radiant heat, emanating from the intensely hot matter of the sun.

The conception of the "sorting demon" is purely mechanical, and is of great value in purely physical science. It was not invented to help us to deal with questions regarding the influence of life and of mind on the motions of matter, questions essentially beyond the range of mere dynamics.

The discourse was illustrated by a series of experiments.

\section{PAOLO VOLPICELLI}

THIS eminent Italian physicist, whose death we recently recorded, was born at Rome on January 8, 1804 . He lost his mother a few days after his birth; his father was Prof. Alexander Volpicelli, a member of the Medical College of the Roman University. Paolo was educated at the college of Veroli and the University of Rome, where, in accordance with the wish of his father, he commenced the study of medicine, but abandoned it after the first year, declaring that medicine was not a science. Of his own accord he applied himself seriously to the course of mathematical philosophy, and four years later received the degree of doctor ad honorem in that faculty. It should be mentioned that doctorates ad honorem are given to only two students each year, and Volpicelli's fellow-doctor was the eminent Professor Tortolini, who followed the same course. Before leaving the University his professors recommended him to the Government for a scientific position. In fact, Prof. Morichini wished to name him his successor to the Chair of Chemistry in the University of Rome, but Volpicelli preferred to succeed Dr. Barlocci, Professor of Experimental Physics in the same University, and in 1845 , on the death of Barlocci, became titular professor. Volpicelli occupied this chair till 1873, when he was appointed Professor of Mathematical Physics in the same University. In $185 \mathrm{I}$ he was made a member of the Philosophical College, an honour accorded to only twelve professors of the University of Rome. Besides his position at this University, Volpicelli also filled that of Professor of Mathematical Physics at the Roman Seminary, taught geometry to the pupils of St. Michael's Hospital, and founded at Rome the special School of Artillery, of which he was director for thirty years.

When Pope Pius IX. revived the celebrated and historical Lincei Academy in 1847 , Volpicelli was appointed secretary, a post which he held for thirty years, when, as his health was failing, the academicians made him secre- 